\section{Pediatric Review - International Journal of Pediatric Research}

\title{
Evaluation of integrated teaching among undergraduate medical students: A step towards competency-based medical education.
}

\author{
Gupta R. ${ }^{1 *}$, Sathe S. ${ }^{2}$, Pandey M. ${ }^{3}$, Mehta A. ${ }^{4}$ \\ DOI: https://doi.org/10.17511/ijpr.2020.i08.11
}

1* Rajesh Gupta, Professor, Department of Pediatrics, Government Medical College, Datia, Madhya Pradesh, India.

2 Sameer Sathe, Professor, Department of Anatomy, Government Medical College, Datia, Madhya Pradesh, India.

3 Mukesh Pandey, Associate Professor, Department of Physiology, Government Medical College, Datia, Madhya Pradesh, India.

${ }^{4}$ Abhishek Mehta, Associate Professor, Department of Microbiology, Government Medical College, Datia, Madhya Pradesh, India.

Background: Didactic lectures are one of the most widely used teaching methods in Indian Medical Colleges. An integrated approach can make medical teaching more interesting and skill-oriented to the faculty as well as students. Aim \& Objective: To evaluate integrated teaching in medical education assessing existing knowledge of medical students' inappropriate breastfeeding practices. Methodology: This was an observational cross-sectional study. Participants were second phase medical students. The sharing method of integrated teaching was used involving the Department of Anatomy, Physiology, and Pediatrics. Students were evaluated for their knowledge on the topic before and after the integrated teaching session through a predesigned pre-validated MCQs based questionnaire. Feedback of students was taken on Likert's scale. The analysis was done using a Student paired t-test. Results: A total of 63 students were assessed for the topic with pretest and post-test. Student Paired t-test showed extremely statistically significant two-tailed P-value (< $0.0001) .76 \%(n=48)$ of students were strongly agreed with such integrated teaching sessions. $55.5 \%(n=35)$ strongly felt its usefulness and 95\% $(n=60)$ agreed about the conduction of such more sessions in the future too. Conclusion: Statistically significant absolute learning gain was observed for integrated teaching. Integrated teaching has been appreciated and accepted by undergraduate medical students to improve their learning.

Keywords: Integrated teaching, Competency, Medical education, Undergraduate

Corresponding Author

Rajesh Gupta, Professor, Department of Pediatrics, Government Medical College, Datia, Madhya Pradesh, India.

Email: drrajesh93@gmail.com
How to Cite this Article

To Browse

Gupta R, Sathe S, Pandey M, Mehta A. Evaluation of integrated teaching among undergraduate medical students: A step towards competency-based medical education.. Pediatric Rev Int J Pediatr Res. $2020 ; 7(8): 452-455$

Available From

https://pediatrics.medresearch.in/index.php/ijpr/arti

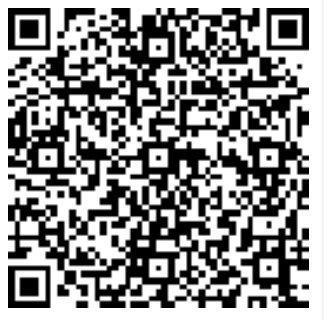
cle/view/648

Review Round 3 


\section{Introduction}

Competency-based medical education (CBME) has been defined as an outcome-based approach to the design, implementation, assessment, and evaluation of a medical education program using the organizing framework of competencies [1]. Thus, it is more about the integration of the required knowledge, skills, and attitudes rather than any one of them in isolation [2].

Integration in medical education can be conceptualized as similar, overlapping, or redundant topic/organ system are merged into a single teaching session in which subject-based demarcations are removed [3]. The importance of individual subjects is subordinated with the integration of several subjects to achieve the main goal of training a functional physician [4].

The competency-driven curriculum imparts innovations to use interactive teaching methods in a large classroom for a more student-centered approach to deliver the core knowledge with sound concepts of the subject [5].

Medical council of India has proposed Alignment and Integration to the extent possible as an opportunity to understand the interconnectedness and reduce redundancy in the subjects being taught through Graduate Medical Education Regulations (GMER) 2019.

This study was conducted to find out the scope of integrated teaching and its acceptance in undergraduate medical teaching.

\section{Material and Method}

This observational cross-sectional study was conducted at the Department of Pediatrics, Government Medical College, Datia, MP after taking approval from the institutional ethics committee and after seeking written informed consent from participants.

Aims \& Objectives of this study were:

1) To assess existing knowledge of medical students inappropriate breastfeeding practices; and

2) To evaluate the benefit of integrated teaching in medical education.

This study was conducted on the students of the ongoing Second MBBS batch using Convenience sampling.
A detailed lesson plan was drafted and a teaching session was conducted on the topic "Appropriate breastfeeding practices in lactating mothers" through the 'Sharing' method of integrated teaching involving Departments of Anatomy, Physiology, and Pediatrics.

Students were evaluated for their existing knowledge on the topic before the session and after the integrated teaching session through a predesigned pre-validated MCQs based questionnaire. Pre-validation of MCQs was done among a peer group of faculty and subject experts.

The questionnaire with 30 MCQs to be solved in 30 minutes, was administered to all the participants before the teaching session. Thereafter integrated teaching was conducted.

Faculty from the Department of Anatomy described Breast tissue structure, Mechanism of milk production and ejection was explained by Physiology faculty; Role of correct breastfeeding practices and its public health aspect was taught by Pediatrics faculty.

Each teacher addressed the doubts and queries related to their subject after the session. The same questionnaire was administered as a post-test to all the students. Feedback of students, as well as teachers about the session, was elicited on 5 points Likert's scale. Statistical analysis was done using a paired t-test.

\section{Results}

A total of 63 students have attended teaching sessions. Pre-test and Post-test results. The twotailed P-value is less than 0.0001 which is conventionally considered to be statistically extremely significant. The mean of Pre-Test minus Post Test equals -3.71 . 95\% confidence interval (CI) of this difference is from -4.89 to -2.54 (Table 1 ).

Feedback of students was assessed over Likert's scale and $76 \%(n=48)$ of students were 'strongly agreed' with learning through such integrated teaching sessions. $55.5 \% \quad(n=35)$ strongly felt its usefulness and $95 \% \quad(n=60)$ agreed about the conduction of such more sessions in the future too.

All three faculties felt that such sessions not only improve their understanding of the subject through sharing but also improved bonding among faculty. 
Table-1: Paired t-test results

\begin{tabular}{|l|l|l|}
\hline \multicolumn{2}{|c|}{ Parameter } & \multicolumn{1}{c|}{ Value } \\
\hline 1 & Two tailed P value & $<0.001$ \\
\hline 2 & Confidence interval (C.I.) & -3.71 \\
\cline { 2 - 3 } & Mean of pre-test minus post test & From -4.89 to -2.54 \\
\hline \multirow{2}{*}{3} & $95 \%$ confidence interval of this difference & Intermediate value used in calculations: \\
\cline { 2 - 3 } & t & 6.3253 \\
& df (degree of freedom) & 62 \\
& standard error of difference & 0.587 \\
\hline
\end{tabular}

\section{Discussion}

This study was carried out given the recent introduction of new Competency-based medical education in undergraduate teaching [2] for identifying innovative methods of teaching with vertical integration of various fields of learning over a common topic apart from the traditional way of teaching by didactic lecture only. The outcome of this study shows that students are more receptive towards Integrated teaching which has significant academic benefits in terms of enhanced learning and better conceptualization.

A study from South India by $\mathrm{T}$ Muthukumar et.al. showed a statistically extremely significant increase in the knowledge in pre and post-test scores among 68 students in their study conducted to find out the scope of integrated teaching in the undergraduate medical curriculum [6]. IAP guidelines Graduate medical education in Pediatrics recommends that the training in Pediatrics should be done in an integrated manner with other disciplines to prepare the student to deliver preventive, promotive, curative, and rehabilitative services for the care of children both in the community and at the hospital as part of a team [7].

This study followed the concept of vertical integration through organizing a teaching session over a relevant pediatric topic of social interest including faculty from Anatomy and Physiology apart from Pediatrics to cover their respective disciplinary part for the topic.

Integration is a learning experience that allows the learner to perceive relationships from blocks of knowledge and develop a unified view of its basis and its application [3]. Our study experienced this basic concept of integration. Students had a chance to get exposure to three different subject experts to solve their queries at the same time which is reflected by their feedback. This also allowed faculty to learn from each other.
MCI has adapted a need-based curriculum for undergraduate medical education in India as medical Colleges usually follow a traditional curriculum with a high degree of compartmentalization of subjects as basic sciences, pre-clinical, para-clinical, and clinical branches which leads to unnecessary repetition. Students may be confused due to differences of opinion and lack of coordination amongst faculty at different phases, leading to improper conceptualization, and may face difficulty in applying knowledge into the practice [8].

This study finds that in the presence of different subject experts, the topic is made easy to understand with the prompt solution of queries. Basic subject experts are the first encountered faculty for undergraduate students in any medical college. The student-teacher bonding at this phase is at a different level which makes them comfortable to ask queries as reflected by the students' feedback.

\section{Conclusion}

Integrated teaching has been appreciated and accepted by undergraduate medical students to improve their learning. An integrated teaching approach needs to be promoted in san undergraduate medical curriculum with appropriate sensitization of the faculty and students.

\section{Author's Contribution}

Dr. Rajesh Gupta: Study concept study design

Dr. Sameer Sathe: Integrated teaching session, data collection

Dr. Mukesh Pandey: Statistical analysis

Dr. Abhishek Mehta: Manuscript writing

\section{Reference}

01. Frank JR, Snell LS, Cate OT, Holmboe ES, Carraccio C, Swing SR, et al. Competency-based medical education- Theory to practice. Medical Teacher. 2010;32(8)638-645.

doi: $10.3109 / 0142159 \times .2010 .501190 \quad$ [Crossref]

02. Medical Council of India. Assessment Module for Undergraduate Medical Education Training Program. 2019;1-29.

[Crossref] 
03. Medical Council of India. Alignment and Integration Module for Undergraduate Medical Education Program. 2019;1- 34.

[Crossref]

04. Haranath P. Integrated teaching in medicine Indian scene. Indian J Pharmacol. 2013;45(1)13.

doi: $10.4103 / 0253-7613.106425$ [Crossref]

05. Bhuiyan P, Supe A, Rege N. The Art of Teaching Medical Students. New Delhi-Elsevier Health Sciences. 2015;2;305-12.

[Crossref]
06. Muthukumar T, Konduru RK, Manikandan M, Asir J, Iqbal N, Bazroy J, et al. Scope of integrated teaching in a medical college- A study from South India. J Med Soc. 2017;31(1)127-130.

doi: 10.4103/jms.jms_98_16 [Crossref]

07. Shrivasrava RN, Mittal SK, Paul VK, Ramji S. Recommendations- IAP guidelines Graduate medical education in Pediatrics. Indian Pediatr. $2001 ; 38 ; 605-618$.

[Crossref]

08. Khullar S. Integrated teaching in medical education in India. Int J Basic Appl Physiol. 2016;5(1)6-14.

[Crossref] 